\title{
Combined surgical and endoprothesical approach to solve a thoracic aortic pseudoaneurysm 15 years after coarctation correction
}

\author{
Ramiro de la Llana, MD, ${ }^{\text {a }}$ Rafael Martínez-Sanz, MD, ${ }^{a}$ Francisco Díaz-Romero, MD, ${ }^{\mathrm{b}}$ Ibrahim Nassar, MD, ${ }^{\mathrm{a}}$ and \\ Pilar Garrido, MD, ${ }^{a}$ Tenerife, Spain
}

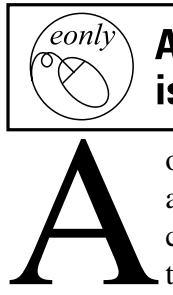

\section{Additional material is available online.} report our experience in a patient with an aortoaortic bypass as a previous step to obliterate the aortic segment with the pseudoaneurysm by means of endoprothesical device insertion.

\section{Clinical Summary}

A 31-year-old patient came to the hospital presenting with high fever and hemoptysis for the last 6 days. He followed a 7-day cycle of amoxicillin (INN: amoxicilline) ordered by his physician, but he felt worse and came to the hospital. When the patient was 16 years old, he had an aortic coarctation correction involving an aortoplasty with a Dacron fabric patch. On arrival, he was febrile, had a murmur audible along the whole chest and in the interscapular space, and complained of cough, dysphonia, and hemoptysis. The chest x-ray film showed a big mass occupying the whole top of the left hemithorax, which corresponded with an enormous aortic pseudoaneurysm arising after a hypoplastic aortic arch (Figure 1). Because contention was considered to be due to the adhesions from the preceding thoracotomy, an extra-anatomic bypass with ligature of the aortic segment where the pseudoaneurysm arose was planned.

During extracorporeal circulation, an aortic anastomosis arising at the aortic arch just below the brachiocephalic trunk was performed, and a Hemashield 20-mm Dacron graft (Boston Scientific Co) was placed, contouring the right border of the heart, and was reanastomosed to the aortic segment behind the heart. Dissection of the aorta at this level was easily performed by means of cephalad retraction of the heart. Aortic arch ligation was then performed before the left subclavian origin, as well as over the

\footnotetext{
From the Departments of Cardiovascular Surgery and Interventional Radioangiology, Hospital Universitario de Canarias, Universidad de La Laguna, Tenerife, Spain.

Received for publication May 31, 2005; revisions received June 15, 2005; accepted for publication June 28, 2005.

Address for reprints: Ramiro de la Llana, MD, Ave de la Asunción 2, $2^{\circ} \mathrm{A}$, 38006 Sta, Cruz de Tenerife, Spain (E-mail: rllana@comtf.es)

J Thorac Cardiovasc Surg 2005;130:1224-5

$0022-5223 / \$ 30.00$

Copyright (C) 2005 by The American Association for Thoracic Surgery doi:10.1016/j.jtcvs.2005.06.025
}
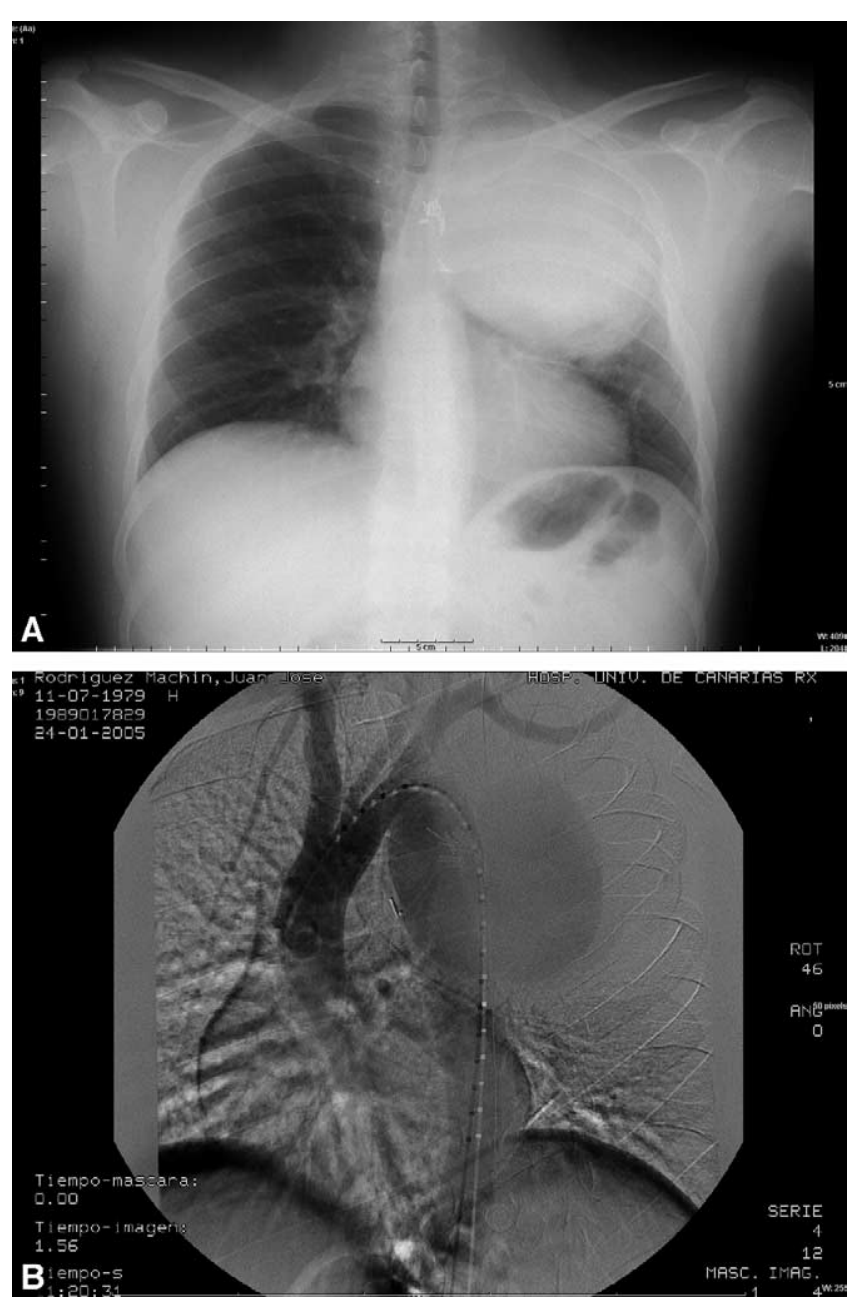

Figure 1. A, Chest x-ray film showing a big mass occupying most of the left upper hemithorax. $B$, Arteriography showing the mass as a big aortic pseudoaneurysm.

retrocardiac graft anastomosis by using 2 Ti-cron 0 sutures braided as a single thread. The left subclavian artery was also ligated at its origin with the same thread (Figure E1). Once the heparin was reverted, 5000 units of thrombin was injected in the pseudoaneurysmal cavity, and the patient's chest was closed in a routine manner.

After the operation, extubation was attempted without success at 3 different times. A scanner showed partial recanalization of the excluded aorta, and the base of the pseudoaneurysm was seen to be 

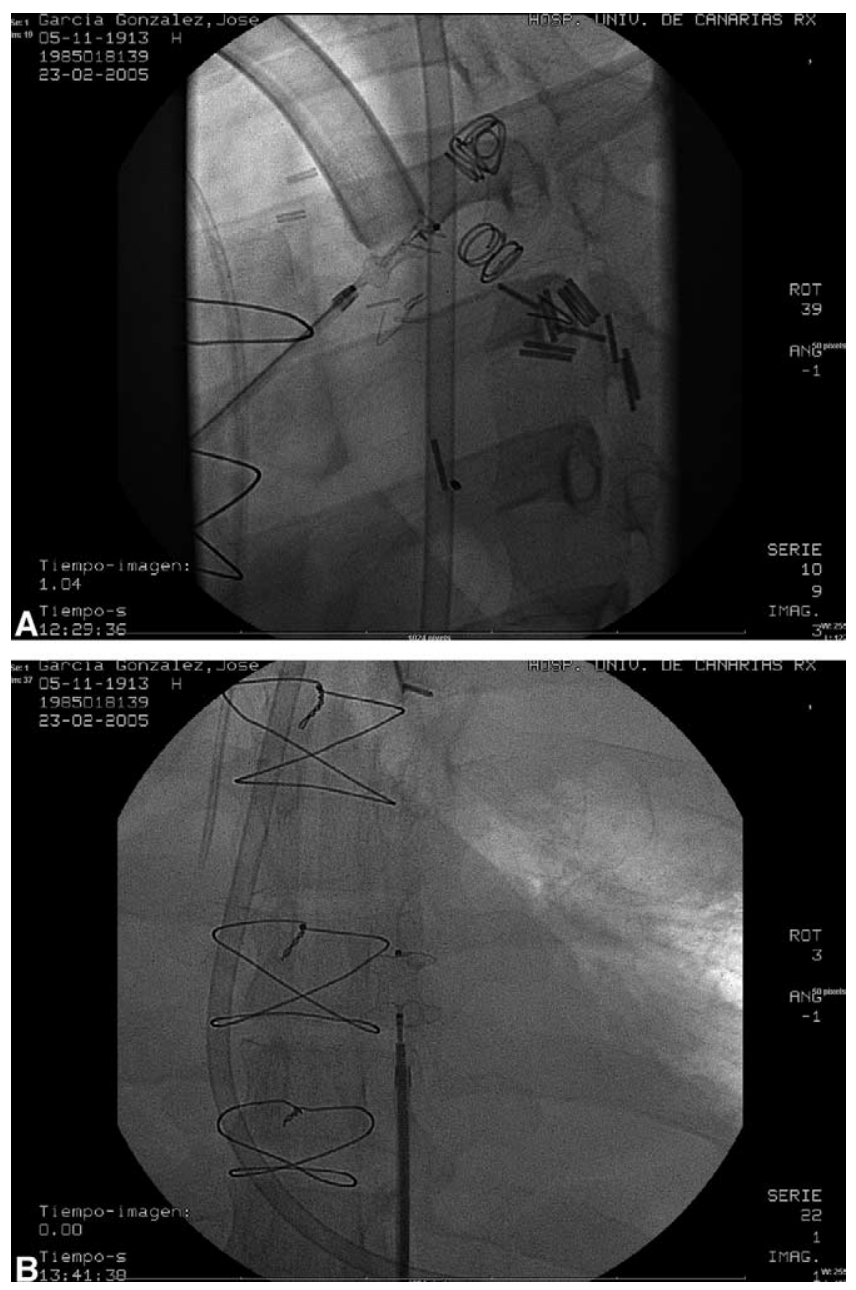

Figure 2. A, Insertion of the proximal occluder. B, Insertion of the distal closing device.

growing and permeable. The left subclavia was also patent. By means of coil plus thrombin injection through an interventional catheter, total clotting of the subclavian stump was achieved, but the aortic excluded segment remained partially permeable, even if new thrombin and coil injections were performed in the same manner.

Twenty days after the derivative operation, an Amplatzer $8 \mathrm{~mm}$ vascular occluder (AGA Medical Co) was inserted in the proximal communication of the aortic excluded segment. In the same procedure, a 12-mm Amplatzer device designed for atrial septal defect closure was set in the inferior aortic stricture (Figure 2). The excluded aortic segment was again filled with thrombin to occlude this segment, as well as its intercostal arteries.

On the next day, a left fourth intercostal thoracotomy was performed to reach an enormous pseudoaneurysm impossible to dissect away from the left pulmonary culmen, which had to be removed together, as well as a great deal of the left upper lobe. The Dacron fabric patch was found imbedded in the clots forming the pseudoaneurysm. No positive cultures were obtained from the different tissues sent for bacteriologic hatching.

In a few days, the patient could be weaned away from endotracheal positive pressure ventilation, made a total recovery, and was discharged.

\section{Discussion}

When a thoracic pseudoaneurysm is considered to be contained by the adhesions of the preceding thoracotomy and the pulmonary stroma, its surgical approach means a great challenge. ${ }^{1-5}$ Some authors have used deep hypothermic arrest for opening and removing the pseudoaneurysm, ${ }^{3}$ but most others suggest the use of extra-anatomic bypass to jump over the injured aortic segment. ${ }^{4,5}$ In our case, the use of the bypass had to be followed by an aortic ligation, which is very difficult to achieve in a manner that is tight enough to avoid blood passage. In fact, every ligature showed permeability 1 week after creation, and the pseudoaneurysm was filled with pressured blood and kept growing. The less dangerous solution found was the use of endovascular occluders in the aortic strictures caused by the ligatures. The proximal stricture was closed with an endovascular occluder. The inferior stricture was filled with an atrial septal defect closure device, which was considered the best to close the sandglass segment of the ligated aorta. Once the segment totally clotted, a left thoracotomy could be performed securely because no pressure was in the pseudoaneurysm or in the intercostal arteries.

\section{References}

1. Posacioglu H, Apaydin AZ. Pseudoaneurysm and aortobronchial fistula after aortic coarctaction repair by patch aortoplasty. Tex Heart Inst J. 2004;31:319-21.

2. Carrel TP, Berdat PA, Baumgartner I, Dinkel HP, Schmidli J. Combined surgical and endovascular approach to treat a complex aortic coarctation without extracorporeal circulation. Ann Thorac Surg. 2004; 78:1462-5.

3. Martin-trenor A, Lopez Coronado JL, Martinez Caro D, Saenz de Buruaga JD. Large false aortic aneurysm after 30 years of a coarctation repair. Rev Med Univ Navarra. 2003;47:34-6.

4. Kanter KR, Erez E, Williams WH, Tam VK. Extra-anatomic aortic bypass via sternotomy for complex aortic arch stenosis in children. J Thorac Cardiovasc Surg. 2000;120:885-90.

5. Weldon CS, Hartmann AF, Steinhoff NG, Morrisey JD. A simple, safe, and rapid technique for the management of recurrent coarctation of the aorta. Ann Thorac Surg. 1973;15:510-9. 

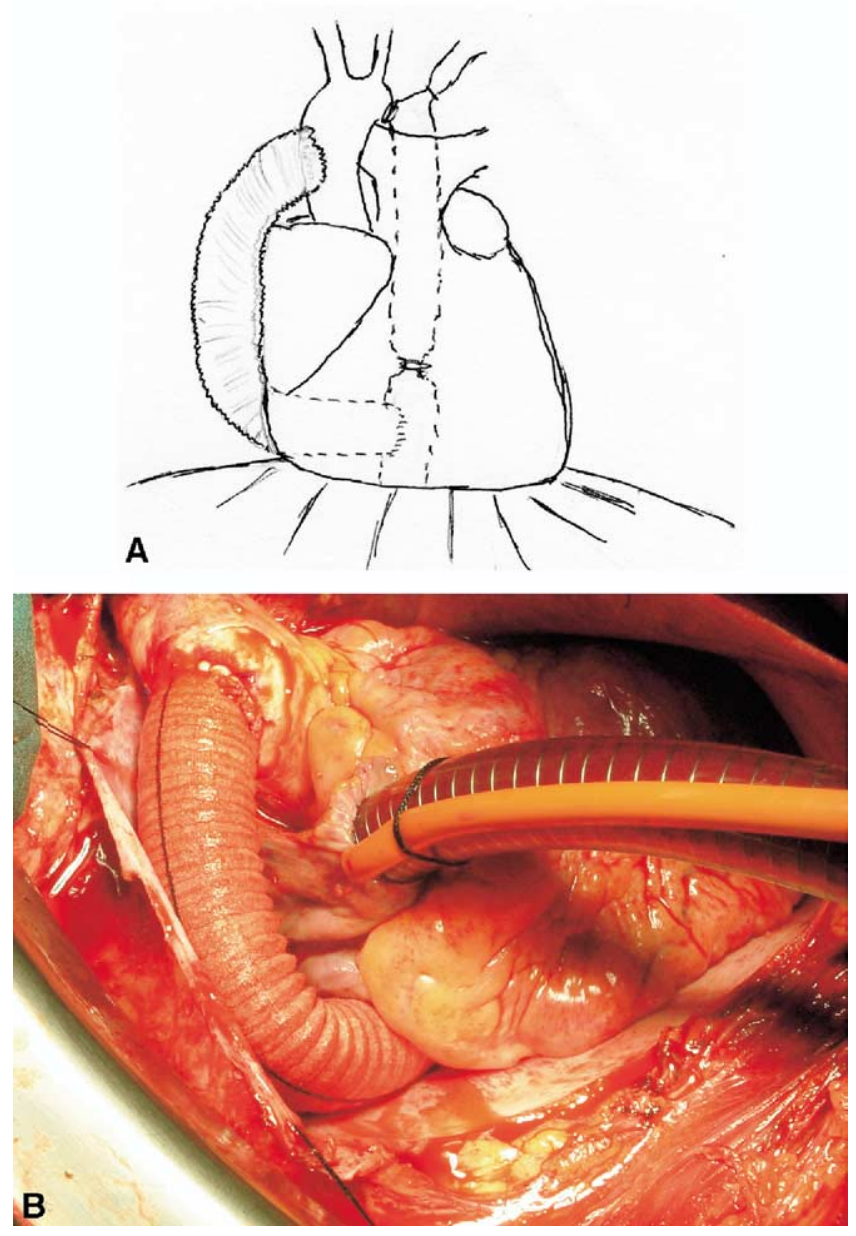

Figure E1. A, Schematic figure of the real image seen at the bottom. B, Aortoaortic bypass. 